\title{
Evaluation of Suitability of Wheat Bran as a Natural Filler in Polymer Processing
}

\author{
Łukasz Majewski ${ }^{\mathrm{a}, *}$ and Antonio Gaspar Cunha ${ }^{\mathrm{b}}$
}

\begin{abstract}
The promotion of sustainable economic development and issues related to ecological and environmental protection has led to a common interest in the use of raw materials from renewable sources. Recently, there have been many scientific works on the use of different natural wastes as components in the production of new composite materials and polymers. An example of natural waste that is not managed efficiently is grain husk, which is a by-product of the production of flour and other products. This work studied the use of wheat grain husk for plastic processing. A short review is presented of studies concerning the use of natural waste and materials as fillers for natural and synthetic polymers, as well as their potential applications. The authors conducted original research on the influence of the mass fraction and particle size of wheat bran on the selected properties of low-density polyethylene, which can be useful in the evaluation of the suitability of this raw material for particular technical applications.
\end{abstract}

Keywords: Biofiller; Wheat bran; Natural filler; Renewable raw materials; Injection molding

Contact information: a:Department of Technology and Polymer Processing, Mechanical Engineering Faculty, Lublin University of Technology, 38D Nadbystrzycka str., Lublin, 20-618Poland; b:Institute of Polymers and Composites, Department of Polymer Engineering, University of Minho, 4800-058Guimarães, Portugal; *Corresponding author: l.majewski@pollub.pl

\section{INTRODUCTION}

Injection molding is one of the most popular method of polymer processing. This is mostly because of the short duration of the process, a vast variety of application possibilities, and high performance precision regardless of the plastic used (Osswald et al. 2001). The use of unmodified polymers has been insufficient to meet the current requirements for both construction and economic aspects. Modified plastics are becoming more popular as a result of pressure to lower production costs caused by increasing demand for materials with specific and unprecedented properties, as well as because of production volumes (Katz and Milewski 1987; Rothon 2003). To achieve various polymer properties, they need to undergo chemical or physical modification, reactive processing, or supplementation with a filler or auxiliary reagent (Katz and Milewski 1987; Rothon 1999; Hidayah et al. 2015; Xiang et al. 2015). Polymer composite production is an interdisciplinary issue. While selecting a filler and determining its amount, various factors and parameters must be taken into consideration, including the fields of chemistry, physical chemistry of the polymers, mechanics, rheology, material engineering, and processing machine construction (Katz and Milewski 1987; Chou 1993; Rothon 2003; Sikora and Kapuśniak 2005; Sikora and Sasimowski 2005; Głogowska and Sikora 2017). A suitable filler at a proper proportion enables the selected properties to undergo the desired changes. Polymer composites are used mostly for enhancing properties such as the resilience, hardness, abrasion resistance, tensile and flexural strength, chemical resistance, 
temperature stability, flammability, thermal and electrical conductivity, and many others (Katz and Milewski 1987; Rothon 1999; Rothon 2003; Essabir et al. 2013). In addition to the mechanical and thermal properties and economic factors, ecological and environmental regulations have evidently had an increasing impact on research in the field of polymer composites aimed at innovative solutions with natural resources.

In recent years, a trend has risen in the literature concerning polymer plastic processing, where the use of natural and organic materials and waste in the production of polymer matrix composites has become popular. One reason for this is that international environmental organizations are exerting pressure with respect to ecological issues, including waste storage and disposal, recycling, and the use of natural waste in various branches of industry. The production of high-quality materials with the use of renewable resources and natural waste has become the objective of numerous scientists worldwide who work in the material engineering field and polymer plastic processing. Environmental limitations and strict regulations on composite recycling have led to new ways of employing renewable materials in technical applications. The introduction of fillers and natural fibers to a polymer matrix may result in major benefits with respect to the cost, density, and effect on the environment because of its fast biodegradation compared with that of E-glass and carbon fibers (Hassan et al. 2010; Rao et al. 2010; Essabir et al. 2013).

The increasing use of natural materials in composites production has resulted in the emergence of a new class of materials, namely biocomposites. This group includes materials where at least one phase, i.e. the matrix or filler/reinforcement, is of natural origin (Hassan et al. 2010). The matrix may be comprised of various types of bio-based polymers obtained from renewable resources that are suitable for synthetic polymer processing procedures. Renewable or natural resins obtained from vegetable oils or polysaccharides (such as starch, cellulose, chitosan, etc.), as well as polymers obtained from natural monomers, can replace certain synthetic polymers made from fossil fuels, which are commonly used currently (Chiellini et al. 2004). Reinforcements or fillers in bio-based polymers are the by-products of crops or deliberately processed plant organs. An example of natural reinforcements is plant fibers. Depending on the plant species, fibers may be produced from seeds, stems, leaves, or fruits. However, the fibers that are most frequently used in composites production are obtained from stems and leaves, such as wood, cotton, linen, silk, and kenaf (Hassan et al. 2010; Essabir et al. 2013;Abdul Karim et al. 2016). The mechanical strength of natural fibers is similar to that of certain synthetic fibers, such as E-glass fibers (alumino-borosilicate glass). Fillers are usually loose materials or materials with small dimensions that are suitable for milling. In most cases, these are byproducts of land cultivation, such as fruit seeds and husks, straw and cereal bran, nut shells, crustacean shells, and palm kernel shells (Hassan et al. 2010; Daudet al. 2016). It is well known that the properties of composites and polymer mixtures mainly depend on the type of reinforcement/filler. It is therefore considered necessary to study new polymer compositions and search for new materials with acceptable properties.

Several studies on natural fillers have been conducted to determine their suitability and impact on the properties of a polymer matrix (Essabir et al. 2013). These studies have primarily focused on the selection of an appropriate matrix polymer, mass filler content, and chemical modification. The filler subjected to examination is often selected according to the geographical location and ubiquity of certain plant species in a given geographical zone (Essabir et al. 2013). The processing of various types of cereals, vegetables, fruits, spices, wood, and vegetable fibers on an industrial scale results in large quantities of natural waste in the form of husks, shells, seeds, bran, natural fibers, and sawdust. India and China 
are undeniably the major global producers of rice. It should therefore not be a surprise that much of the scientific research on polymer composites with rice bran and husk is conducted in Asia. For instance, George et al. (2006), a team of researchers from India, studied the influence of rice bran on thin films made of low-density polyethylene(LDPE). Despite the deterioration of the mechanical properties as the content of rice bran increased, the composite could be successfully used in the production of packaging because of better gas transmission and the ability to decompose under biological conditions. Another study conducted by Premalal et al. (2002) in Malaysia compared the properties of polypropylene matrix composites filled with rice husk powder and talc. According to this study, the biocomposite with a $30 \%$ filler mass fraction showed only slightly worse mechanical properties than those of the composite with polypropylene and talc. Rice husk powder was also examined in other studies (Hardinnawirda and SitiRabiatull Aisha 2012; Ramasamy et al. 2013), where the authors found that the rice husk powder acted as a reinforcing filler. Another example of the application of natural fillers is the study conducted by Nuraya et al. (2015), in which a research team compared rubber compounds containing banana powder and calcium carbonate as the filler. It was concluded that despite a poorer tensile strength, the mixture containing banana powder exhibited a greater tear strength. Another example of the use of natural waste as a composite ingredient was elaborated on by a team of researchers from Morocco and France. Essabir et al.(2013) examined the impact of fragmented argan nut shells on the properties of polypropylene. The results obtained showed a clear increase in the mechanical properties during stretching up to a20-wt.\% filler content. Furthermore, the mechanical properties increased as the particle size decreased. It appears that the use of materials with natural origins may result in obtaining desirable and unique properties. Rao et al.(2010) conducted a study on the properties of composite materials with a polyester resin matrix reinforced with vakka, sisal, bamboo, and banana fibers. In addition to satisfactory mechanical properties, the vakka fiber composites exhibited dielectric strength, which means the strength grew as the fiber weight in the composite increased. This phenomenon does not occur frequently in composites with natural fibers. The availability and low price enables vakka fiber composites to be used in the automotive industry and packaging manufacturing. In the production of composites, even spices may prove useful, as evidenced by the study conducted by Jagadish et al. (2009).

One of the most popular crops cultivated in Poland is wheat. It is used mainly for the production of pure white flour. After grinding, grain is called bran remain. In many cases, it is classified as a technological waste, and is available for sale in mills. Unfortunately, there is no accurate data on the amount of wheat bran (WB) in Poland that is produced and unutilized. The Statistical Yearbook of Agriculture, which is published by the Central Statistical Office of Poland, aggregates information on the crop yield and production of the important products from the food and tobacco industry. From 2000 to 2014, the wheat grain yield in Poland increased from 8.5 million tons to 11.6 million tons, which was an increase of $36.7 \%$. The production size of white wheat flour also exhibited a growth trend; from 2000 to 2016, this production increased from 2 million tons to 2.25 million tons, which was an increase of $12.5 \%$. This data, while not exactly specifying the amount of WB produced annually in Poland, allows for the conclusion that its production has increased over the years, and this production could at least be in the hundreds of thousands of tons.

The aim of this study was to determine the suitability of the by-product from the production of white flour, namely finely ground WB, for use as a filler in LDPE. This work 
also determined the influence of WB on selected physical and mechanical properties, as well as the microstructure, which would make it possible to establish the suitability of these polymer composites for technical applications.

\section{EXPERIMENTAL}

\section{Materials}

Test samples were acquired as powdered LDPE under the trade name Dowlex (symbol 2631.10EU,DOW Chemical Company, Schkopau, Germany). The plastic material was used for the rotational molding of thin-walled elements and the injection of components requiring a high measurement accuracy. The properties of the material according to the data provided by the manufacturer is compiled in Table 1.

The filler employed was WB, which was wheat grain husks obtained from a local mill. Wheat bran is a by-product of milling wheat grain into clean white flour. The bran is shaped like thin flakes, up to several millimeters in size. The main component of WB is raw fiber containing several fibrous substances, such as cellulose, lignin, and hemicellulose. It also contains phytic acid, oligosaccharides, and non-starch polysaccharides, as well as small quantities of fats and proteins (Stevenson et al. 2012). The density of the WB was approximately $35 \mathrm{~kg} / \mathrm{m}^{3}$.

\section{Table 1. Selected Properties of the LDPE}

\begin{tabular}{|c|c|c|}
\hline Property & Unit & Value \\
\hline Density & $\mathrm{kg} / \mathrm{m}^{3}$ & 935 \\
\hline Melt Flow Index (MFI)at $190^{\circ} \mathrm{C} / 2.16 \mathrm{~kg}$ & $\mathrm{~g} / 10 \mathrm{~min}$ & 7 \\
\hline Vicat Softening Point A120 & ${ }^{\circ} \mathrm{C}$ & 115 \\
\hline Deflection Temperature Under Load HDT B & ${ }^{\circ} \mathrm{C}$ & 52 \\
\hline Melting Point & ${ }^{\circ} \mathrm{C}$ & 124 \\
\hline Crystallization Point & ${ }^{\circ} \mathrm{C}$ & 110 \\
\hline Hardness, Shore D & ${ }^{\circ} \mathrm{ShD}$ & 56 \\
\hline Tensile Yield Stress & $\mathrm{MPa}$ & 17.8 \\
\hline Ultimate Elongation & $\%$ & 419 \\
\hline
\end{tabular}

\section{Methods}

The preparation of the WB involved milling it into afine powder with the use of a grain mill (H115, POM Augustów, Augustów, Poland) and the fractions were separated by specified particle sizes with a shaker equipped with a column of sieves (LPzE-3e, Multiserw-Morek, Brzeźnica, Poland), in which the material was sieved through meshes of decreasing size. The mesh sizes in the sieves were $0.8 \mathrm{~mm}, 0.6 \mathrm{~mm}$, and $0.4 \mathrm{~mm}$. Three fractions were obtained with the particle sizes of $0.6 \mathrm{~mm}$ to $0.8 \mathrm{~mm}, 0.4 \mathrm{mmto} 0.6 \mathrm{~mm}$, and less than $0.4 \mathrm{~mm}$. The appearance of the particle fractions compared with the LDPE is presented in Fig. 1.

Several prototype series of the ready-made injection molded samples were prepared for research purposes, including a prototype series of samples made with non-filled LDPE and nine prototype series of samples with different particle size fillers and different filler mass fractions. 


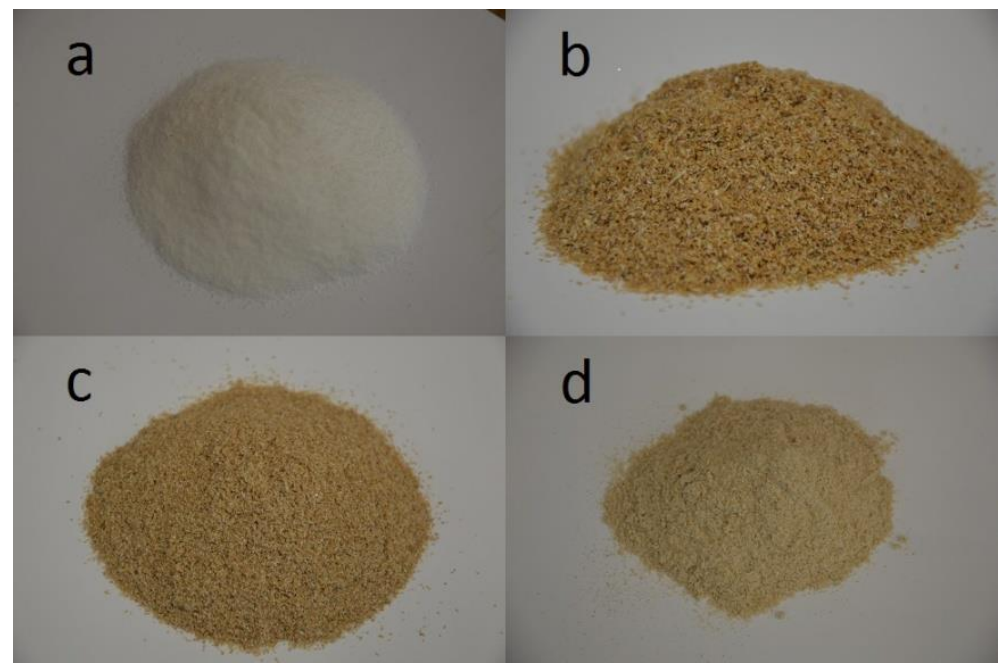

Fig. 1. Appearance of the LDPE (a) and separated WB fractions (b: $0.6 \mathrm{mmto} 0.8 \mathrm{~mm}$; $\mathrm{c}: 0.4 \mathrm{~mm}$ to $0.6 \mathrm{~mm}$; and $\mathrm{d}:<0.4 \mathrm{~mm})$

The powdered LDPE was mixed mechanically in containers with individual WB fractions in three different mass fractions, specifically $5 \mathrm{wt} . \%, 10 \mathrm{wt} . \%$, and $15 \mathrm{wt} . \%$. No pro-adhesive agent was used. The mixtures obtained were then injected with a screw injection molding machine (CS-88/63, KovelisPlasty, Náchod, Czech Republic).The technological parameters of the injection process are compiled in Table 2.

The use of WB as aplastic polymer filler requires processing it at relatively low temperatures because of thermal decomposition of organic substances at higher temperatures, during which gases are intensively produced. The appearances of the readymade injection molded samples are shown in Fig. 2. The dimensions of the forming cavities in the injection mold were compatible with those required by ISO 294-1(2017). A visual assessment of the molds led to the conclusion that the filler was well distributed in the polymer matrix. Furthermore, the particle sizes of the filler and its content affected the color of the molds, which changed from white (pure LDPE) to dark brown. The color was darker when the filler amount was higher and the particle size was larger. Additionally, changes to the surfaces of the samples were visible, such as dulling and a loss of transparency.

Table 2. Technological Parameters of the Injection Molding Process

\begin{tabular}{|c|c|c|}
\hline Parameter & Unit & Value \\
\hline $\begin{array}{c}\text { Temperature in the Particular Zones of the } \\
\text { Plasticizing System }\end{array}$ & ${ }^{\circ} \mathrm{C}$ & $\begin{array}{r}\mathrm{I}-105 \\
\mathrm{II}-130 \\
\mathrm{III}-140\end{array}$ \\
\hline $\begin{array}{c}\text { Temperature of the Injection Nozzle } \\
\text { Mold Temperature }\end{array}$ & ${ }^{\circ} \mathrm{C}$ & 150 \\
\hline Injection Pressure & ${ }^{\circ} \mathrm{C}$ & 40 \\
\hline Cycle Time & $\mathrm{MPa}$ & 100 \\
\hline Cooling Time & $\mathrm{S}$ & 30 \\
\hline & $\mathrm{S}$ & 20 \\
\hline
\end{tabular}




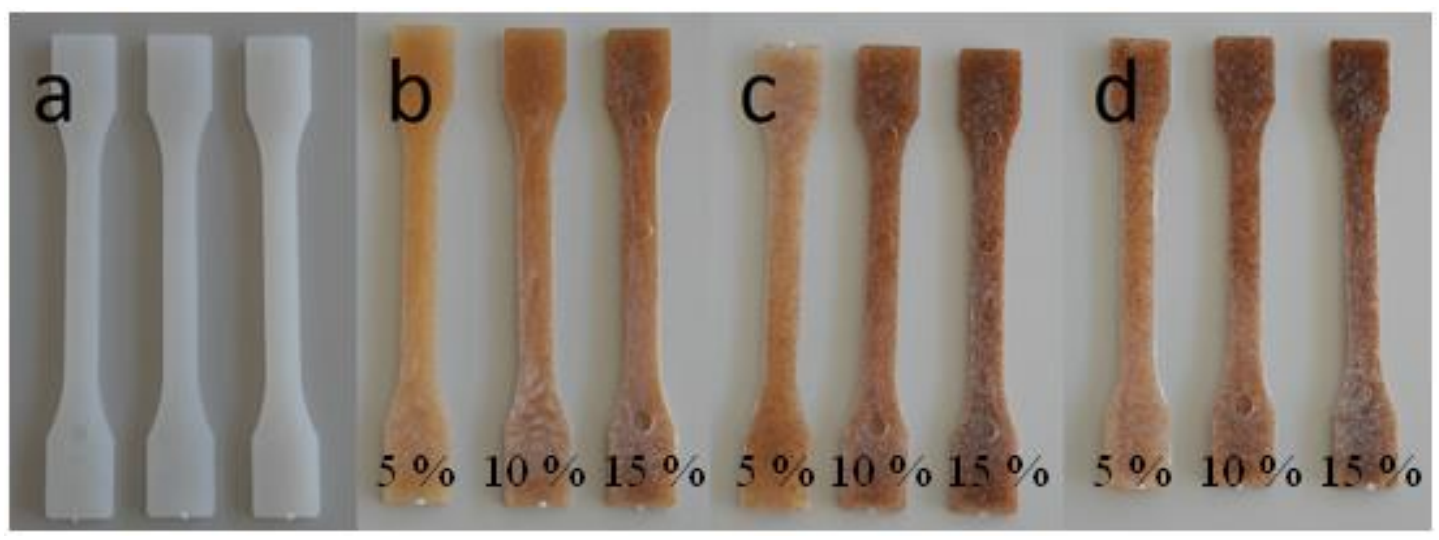

Fig. 2. Appearance of the ready-made injection molded samples: (a) LDPE, (b) LDPE + WB $(<0.4 \mathrm{~mm})$, (c) LDPE + WB $(0.4 \mathrm{~mm}$ to $0.6 \mathrm{~mm})$, and (d) LDPE + WB (0.6 mm to $0.8 \mathrm{~mm})$

The ready-made injection molded samples were subjected to subsequent examinations $24 \mathrm{~h}$ after injection. The longitudinal shrinkage was measured pursuant to the instructions described in ISO 294-4(2001). The normal densities were determined with a pycnometer (Simax 1621/50,Kavalier Glass, Praha, Czech Republic), according to ISO 1183-1(2012).

The cold water absorption was measured pursuant to ISO 62(2008). The Schopper abrasion test was conducted according to ISO 4649(2017). The hardness was measured using the Shore D method, according to ISO 868(2003). The static stretching test was conducted on a strength testing machine (Z010 AllroundLine, Zwick Roel, Ulm, Germany), pursuant to ISO 527-1(2012).

The 100- $\mu \mathrm{m}$ thick samples for the microscopic observation were cut with a microtome (37427, R. Jung, Heidelberg, Germany). Microscopic analysis was conducted on cross-sections of the samples with an Eclipse LV100ND microscope, which was equipped with a DS-U3 camera, and using NIS-Elements AR 4.20.00 software (Nikon Instruments Europe, Amsterdam, Netherlands).

\section{RESULTS AND DISCUSSION}

Based on the measurements and calculation results obtained, relationship charts were prepared for the longitudinal processing shrinkage, normal density, cold water absorption, hardness, Young's modulus, tensile strength, and tear elongation. All of the aforementioned properties were analyzed in relation to the particle size and WB mass fraction.

The relationship between the longitudinal shrinkage and the size of the particle and filler mass fraction is presented in Fig. 3. Increasing the mass fraction of the WB from $0 \mathrm{wt} . \%$ to $15 \mathrm{wt} . \%$ resulted in a linear decrease in the average processing shrinkage. The particle size influenced the scale of this phenomenon. The shrinkage was smaller when the particle size was smaller. Fifteen weight percent WB with the particle size $0.6 \mathrm{~mm}$ to $0.8 \mathrm{~mm}$ led to a slight drop in the shrinkage $(0.09 \%)$ compared with that of the non-filled LDPE, whereas 15 wt.\% WB with particles smaller than $0.4 \mathrm{~mm}$ resulted in a decrease of $2.38 \%$ to $2.15 \%$. 


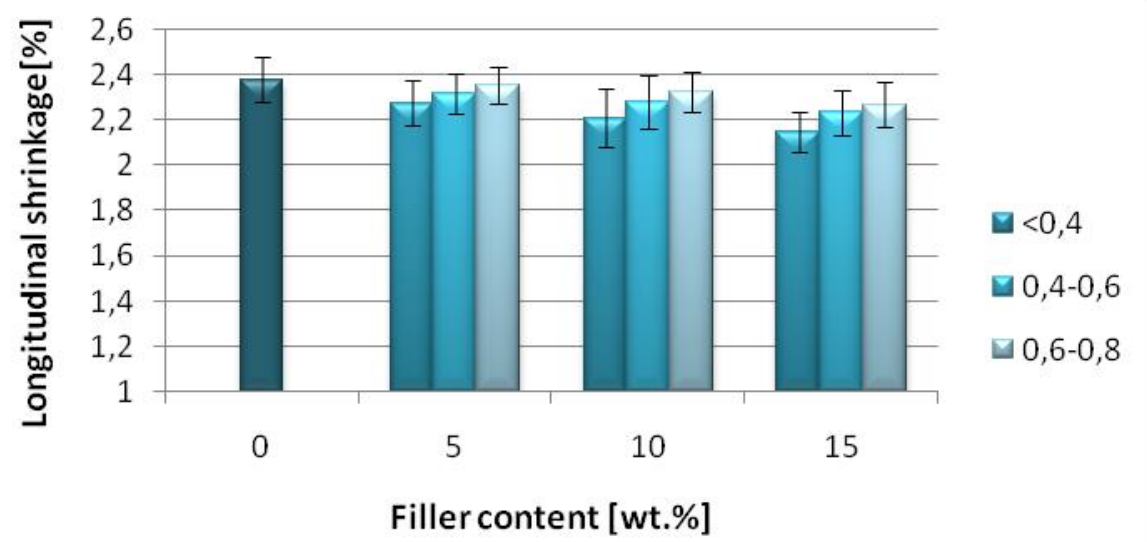

Fig. 3. Relationship between the longitudinal shrinkage and the particle size and WB mass fraction

Adding fillers in the form of powder decreased the shrinkage, as well as the stability. When the filler content is larger, which remains stable with respect to the processing temperature, the dimensions of the molded sample are more stable (Rosato and Rosato 2000; Fisher 2003). The differences in the shrinkage for particular filler fractions may have resulted from different particle shapes. Large particles are shaped like thin flakes, and they are very likely to warp or roll upon application of even a small force. The susceptibility to tensile strain is the same under compression, and the plastic shrinks. The smallest fractions included particles where all three sizes were comparable, and therefore they did not have a surface that would enable them to warp easily under a load. This was probably the reason for the better stability ofthe shape and size, which consequently influenced the shrinkage.

The results of the standard density measurements are presented in Fig. 4 in relation to the particle size and filler mass fraction. Upon increasing the mass fraction of all three WB sizes, the density continuously decreased and reached approximately $90 \%$ of the initial value at $15 \mathrm{wt} . \%$.

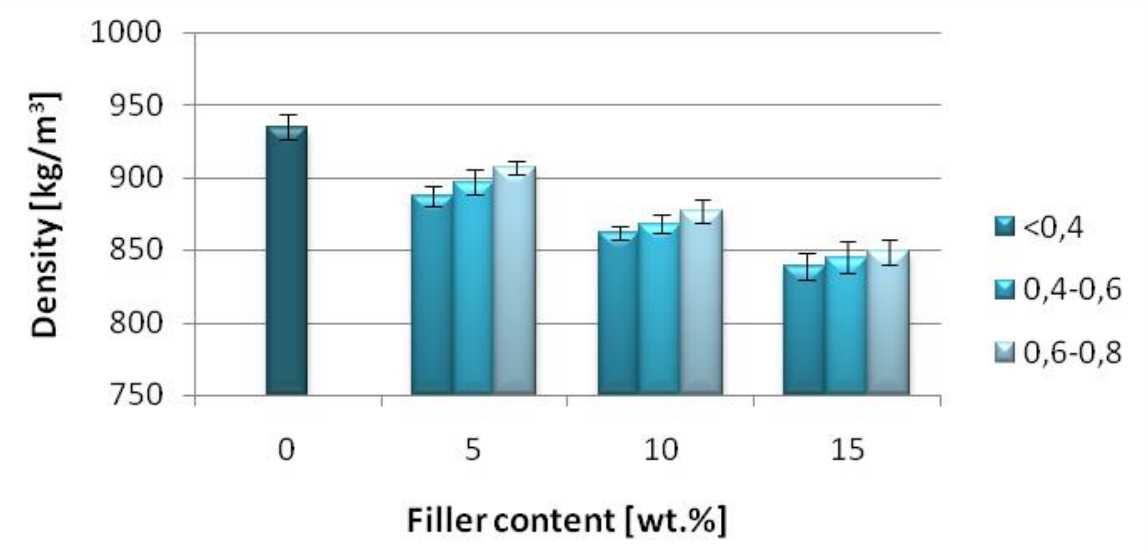

Fig. 4. Relationship between the density and the particle size and WB mass fraction

Slight differences in the density between the individual fractions resulted from the different processing shrinkages, i.e. the greater the shrinkage, the greater the density. 
Because the WB had a lower density (approximately $350 \mathrm{~kg} / \mathrm{m}^{3}$ ) than the LDPE (935 $\mathrm{kg} / \mathrm{m}^{3}$ ), the corresponding decrease in the density with an increase in the filler content was expected.

The relationship between the cold water absorption and the particle size and filler mass fraction is presented in Fig. 5. The chart shows that the WB additive led to an increased capacity of the plastic to absorb water. After 7 days the non-filled plastic exhibited a water absorption level of $0.0028 \mathrm{wt} . \%$. As a result of adding $5 \mathrm{wt} . \% \mathrm{WB}$ $(0.6 \mathrm{~mm}$ to $0.8 \mathrm{~mm})$ to the LDPE, its capacity to absorb water from the ambient environment increased almost nine times. At $15 \mathrm{wt} \%$, this capacity was 12 times higher than that of the non-filled LDPE. The highest WB content of $0.4 \mathrm{~mm}$ to $0.6 \mathrm{~mm}$ particles enhanced the water absorption capacity nine times, whereas the WB with particles smaller than $0.4 \mathrm{~mm}$ improved it seven times.

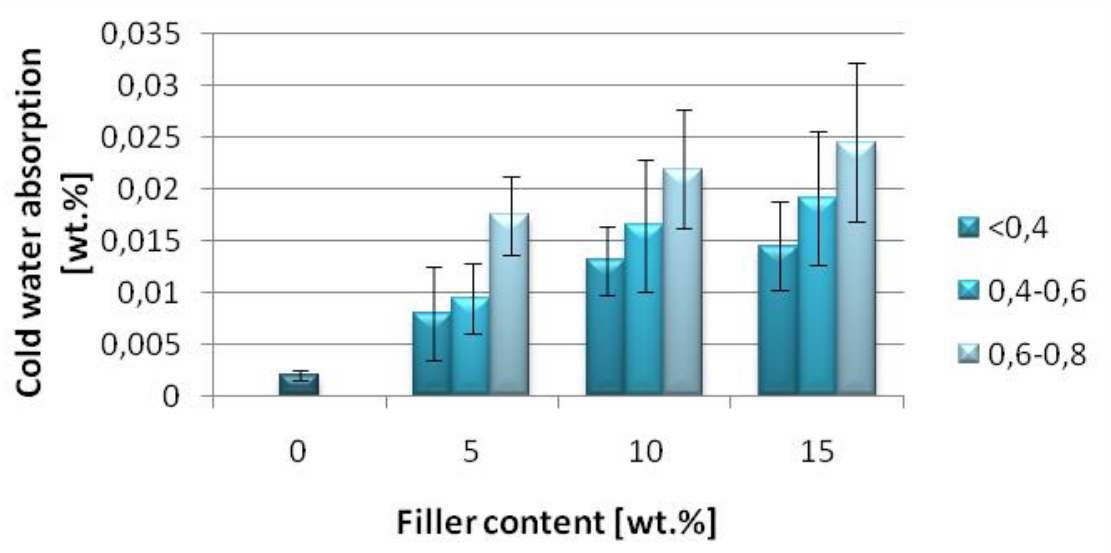

Fig. 5. Relationship between the cold water absorption and the particle size and WB mass fraction

Cellulose and hemicellulose, two main components of WB, are composed of a glucose residue containing polar hydroxyl groups and are highly reactive with water. As a result, the hydrophilic properties enabled the WB to absorb water from the ambient environment (Essabir et al. 2013). The figure also clearly shows the correlation between the particle size and water absorption. When the particles were larger, the water absorption of the LDPE/WB composites was better. An increasing trend in the water absorption was observed in another work (George et al. 2006), which focused on LDPE filled with rice bran. The reason for the large range of results for LDPE with WB was most likely because of the number of filler particles and their arrangement close to the surface of the samples.

Figure 6 presents the graphic relationship between the abrasion and the particle size and WB mass fraction. Increasing the WB mass fraction led to an increased abrasion. Moreover, when the particles were smaller, the abrasion for the 5wt.\% and $10 \mathrm{wt} . \%$ mass fractions was larger. At $15 \mathrm{wt} . \% \mathrm{WB}$, the abrasion for all of the size fractions was similar and ranged from $293 \%$ to $316 \%$ of the abrasion exhibited by the non-filled LDPE.

While it was not the purpose of this work to determine the friction coefficient for each sample, it was concluded that the presence of the powdered WB filler increased the friction coefficient between the molded samples and abrasive material in the SchopperSchlobach apparatus. Their specific surfaces were larger when the WB particles were smaller (Rattanasom et al. 2007). A larger specific surface generates a greater friction 
coefficient and leads to a more effective material selection from the sample through the abrasive cloth on the abrasion testing apparatus.

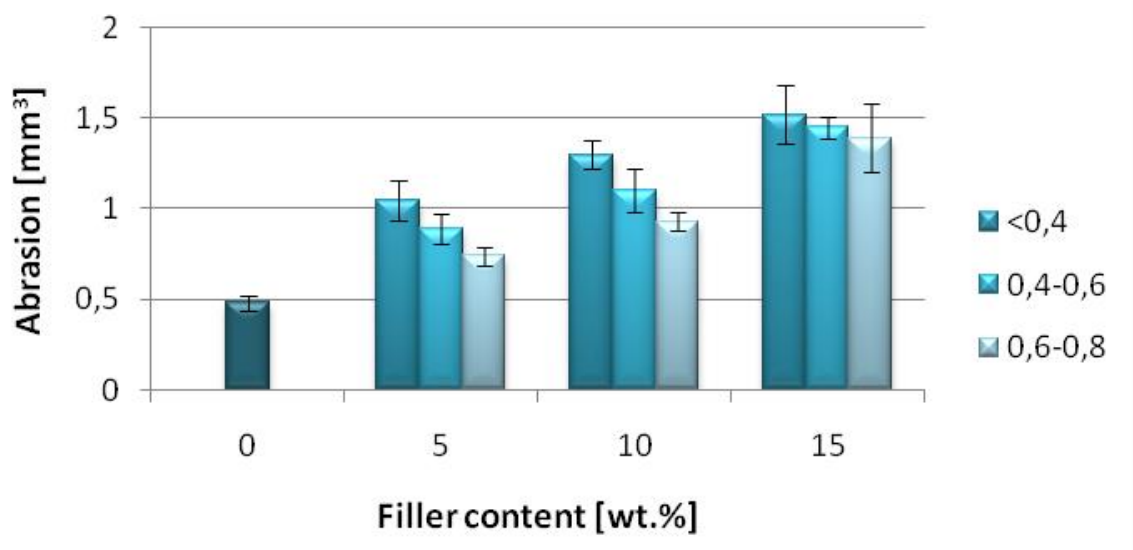

Fig. 6. Relationship between the abrasion and the particle size and WB mass fraction

The results of the hardness examination for particular size fractions and their different mass contents are presented in Fig. 7. The presented data indicated no clear trend. The lowest hardness value was obtained for a polymer mixture containing $15 \mathrm{wt} . \% \mathrm{WB}$ with a particle size smaller than $0.4 \mathrm{~mm}$. This value was $50.9^{\circ} \mathrm{ShD}$, which was $1.7 \%$ lower than the hardness of the non-filled LDPE. With respect of this data, it was concluded that the particle sizes and mass fractions used in the study did not influence the LDPE hardness in any remarkable manner. However, it should be noted that the hardness of the non-filled LDPE was $8 \%$ lower than the value given by the manufacturer. This decrease in the hardness could have been a direct result of processing.

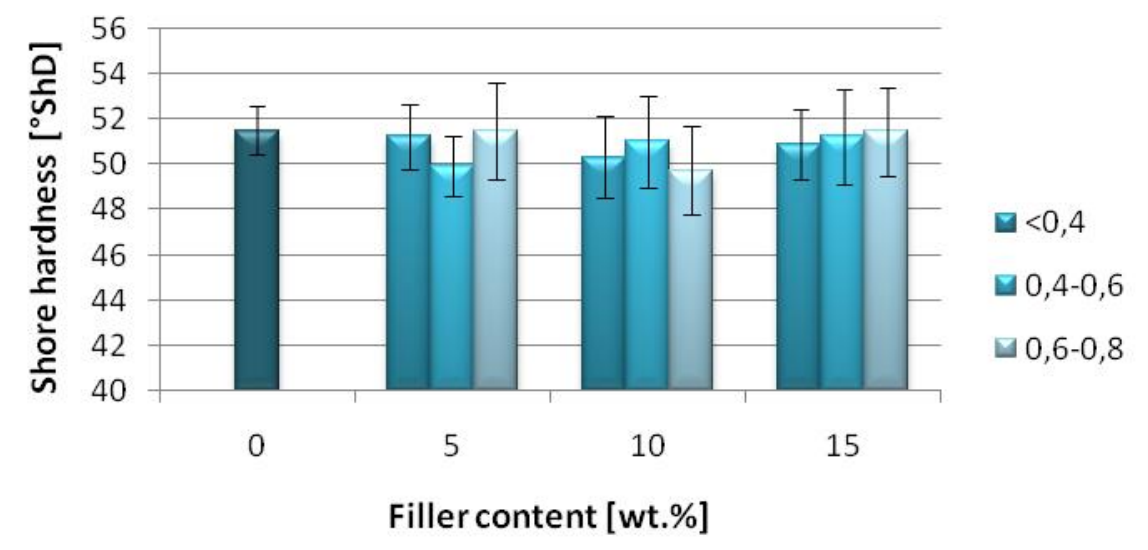

Fig. 7. Relationship between the hardness and the particle size and WB mass fraction

Figures 8, 9, and 10 show the relationships resulting from the static tensile test. Figure 8 presents the changes in the Young's modulus with respect to the mass fraction and WB size fractions. The chart depicts a linear increase in the Young's modulus as the mass fraction of each size fraction increased. The highest increase in the Young's modulus, at $15 \mathrm{wt} . \% \mathrm{WB}$, was observed for the fraction with $0.6 \mathrm{mmto} 0.8 \mathrm{~mm}$ particles. Compared with the non-filled LDPE, this value rose by $62 \mathrm{MPa}$, i.e. $15.5 \%$. 


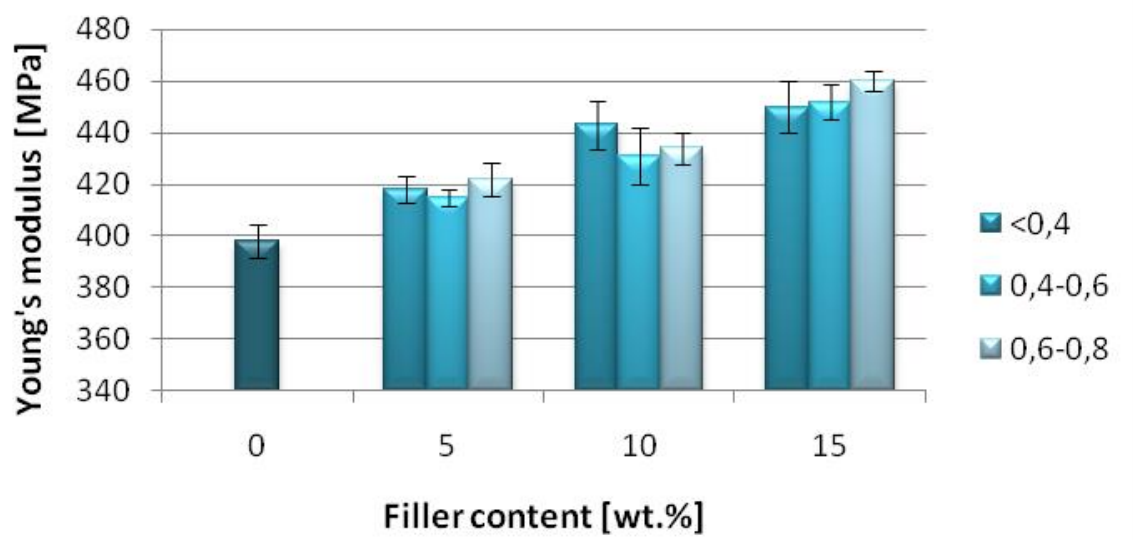

Fig. 8. Relationship between the Young's modulus and the particle size and WB mass fraction

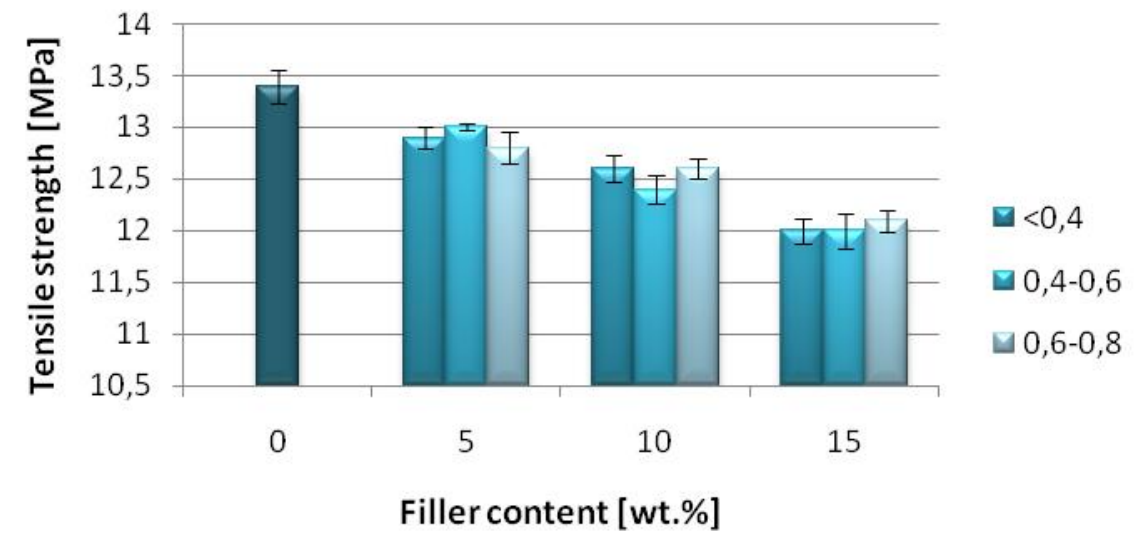

Fig. 9. Relationship between the tensile strength and the particle size and WB mass fraction

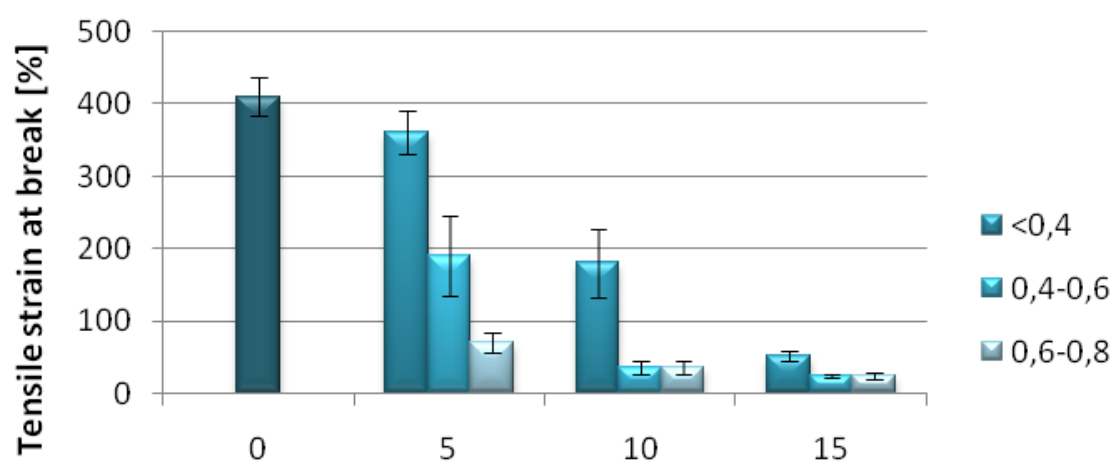

Filler content [wt.\%]

Fig. 10. Relationship between the tensile strain at break and the particle size and WB mass fraction

For the remaining two fractions, the Young's modulus increased to a slightly lesser extent, by $13.5 \%(0.4 \mathrm{~mm}$ to $0.6 \mathrm{~mm})$ and $13 \%(<0.4 \mathrm{~mm})$. As was expected, the tensile strength and resistance to tear elongation, which are presented in Figs. 9 and 10, respectively, decreased as the mass fraction of the WB increased. In the case of the non- 
filled LDPE, the tensile strength was $13.4 \mathrm{MPa}$, and increasing the mass fraction of particular size fractions gradually lowered this value until it reached $11.9 \mathrm{MPa}$ to $12 \mathrm{MPa}$, which was approximately $89 \%$ of its initial value. The particle size did not play a big role in the case of the Young's modulus and tensile strength, but it had a substantial impact on the tear elongation. Five weight percent WB with the particle size of $0.6 \mathrm{~mm}$ to $0.8 \mathrm{~mm}$ resulted in a decrease in elongation from $410 \%$ to $70 \%$. A further increase in the WB mass fraction to $15 \mathrm{wt} . \%$ decreased the tensile strain at break to $22 \%$. With the introduction of a WB additive with particles $0.6 \mathrm{~mm}$ to $0.8 \mathrm{~mm}$ and $0.4 \mathrm{~mm}$ to $0.6 \mathrm{~mm}$ in size to the composition, the tensile strain also decreased, but not as drastically. A gradual increase in the mass fraction led to a decrease in the tensile strain to $190 \%$ (5 wt.\% WB), $44 \%$ (10 wt.\% WB), and 31\% (15 wt.\% WB). This was somewhat different than in the case of the WB with a particle size of less than $0.4 \mathrm{~mm}$. The graph shows the tensile strain decreased noticeably less than for the two larger particle fractions. The $5 \mathrm{wt} . \%$ content decreased the tensile strain to $360 \%$. Further increases of the WB mass fraction decreased the tensile strain to $180 \%$, and it was up to $52 \%$ for the highest WB mass fraction. The same changes to the three properties described above are evidenced in other studies on the impact of various natural fillers on the mechanical properties of polymer composites. Other fillers that have been studied include rice bran (George et al. 2006), rice husk powder (Premalal et al. 2002), wood flakes, sago starch, sisal fibers, and kenaf fibers (Rao et al. 2010).

The Young's modulus characterizes the elasticity of a material, and its growth indicates an increased stiffness and reduced tensile strain under compression. Powder filler particles may act as crystallization nuclei for the polymer in a matrix. A higher degree of crystallinity limits the movement of macromolecules and increases the stiffness. Consequently, the Young's modulus value increases as well (Rothon 1999; Zuiderduin et al. 2003). To improve the stiffness of a polymer composite, it is a prerequisite to obtain an appropriate level of filler dispersion in the matrix (Rothon 1999). The use of a powdered plastic greatly facilitates filler dispersion in the matrix. Apart from filler dispersion itself, the reinforcement mechanisms for polymer compositions with a powdered filler are strictly connected with the size and specific surface of the particles, as well as the type of interaction between the filler and matrix, as this determines the strength of the bond between these two phases (Rothon 1999). The reason for the decrease in the tensile strength for all three filler mass fractions may have been the extensive fluctuation in the particle size, as well as the inconsiderable interaction between the hydrophilic filler and hydrophobic matrix. The mechanism reinforcing the polymers with particles is also connected to the phenomenon of cavitation and stretching of emerging cavities in the direction of a given force acting upon them. A detailed description of this mechanism was given by Kim and Michler (1998) and Tjong (2006). It is commonly assumed that the reinforcement effect occurs in the case of particles smaller than $5 \mu \mathrm{m}$. Otherwise, the emerging cavities may prove too large and consequently cause cracks (Kim and Michler 1998; Zuiderduin et al. 2003). Even a small quantity of excessively large particles may effectively lower the resistance of a composite (Rothon 1999, 2003). Probably it was the particles that were a few tenths of a millimeter in size that caused a remarkable decrease in the tensile strain at break, along with the increase in the mass fraction for all three WB size fractions.

As part of this research, microscopic images of the cross-sections of the samples containing all of the WB particle sizes and fractions were analyzed. Observations of the morphology of the cross-sections of the samples were conducted with an optical microscope. Figures 11through13 juxtapose microscopic images for all three filler particle 
sizes and the 5 wt.\% and 15 wt.\% contents to show the changes in the structure. Each photograph indicates the characteristic sizes of the filler particles present, and their approximate size measured along the longest diagonal is specified.

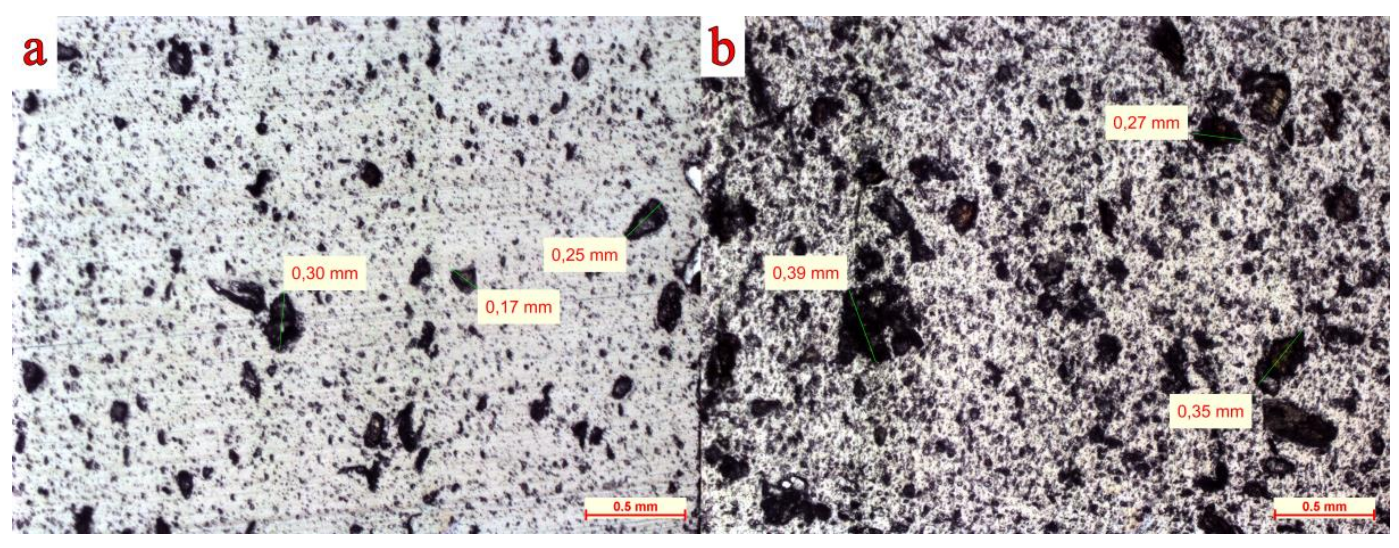

Fig. 11. Microscopic images of microstructures of the LDPE filled with WB with a grain size of less than $0.4 \mathrm{~mm}$ with a $5 \mathrm{wt} . \%$ (a) and $15 \mathrm{wt} . \%$ content (b), dark areas represent WB

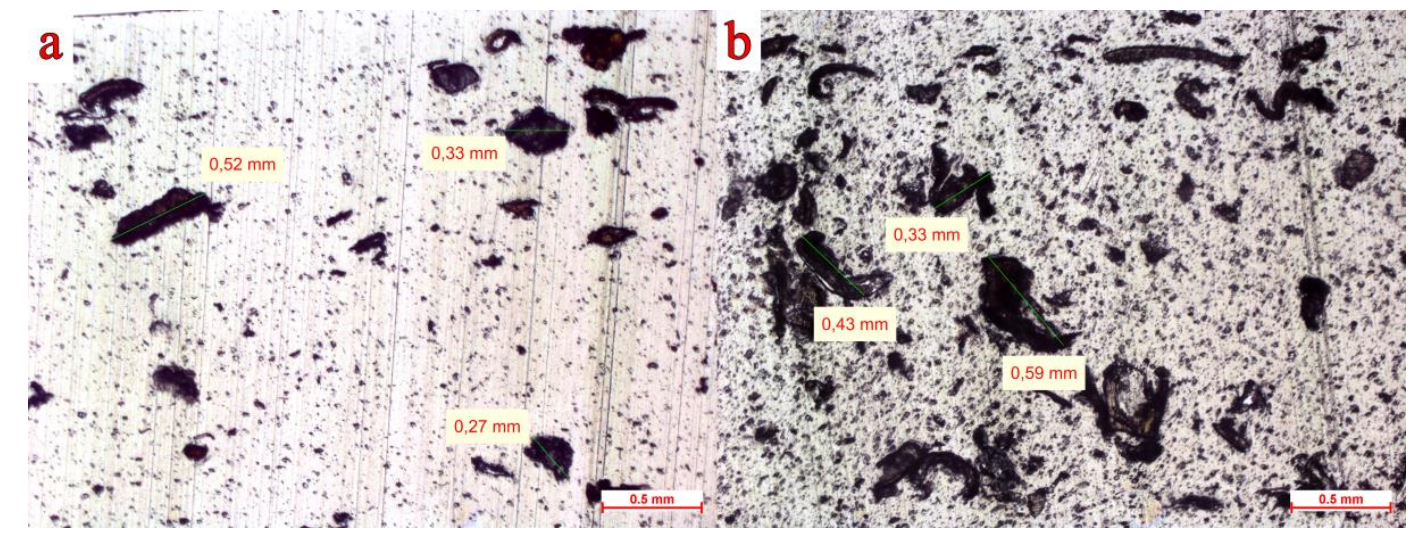

Fig. 12. Microscopic images of microstructures of the LDPE filled with WB with particle sizes in the range of $0.4 \mathrm{~mm}$ to $0.6 \mathrm{~mm}$ with a $5 \mathrm{wt} . \%$ (a) and $15 \mathrm{wt} . \%$ content(b), dark areas represent WB

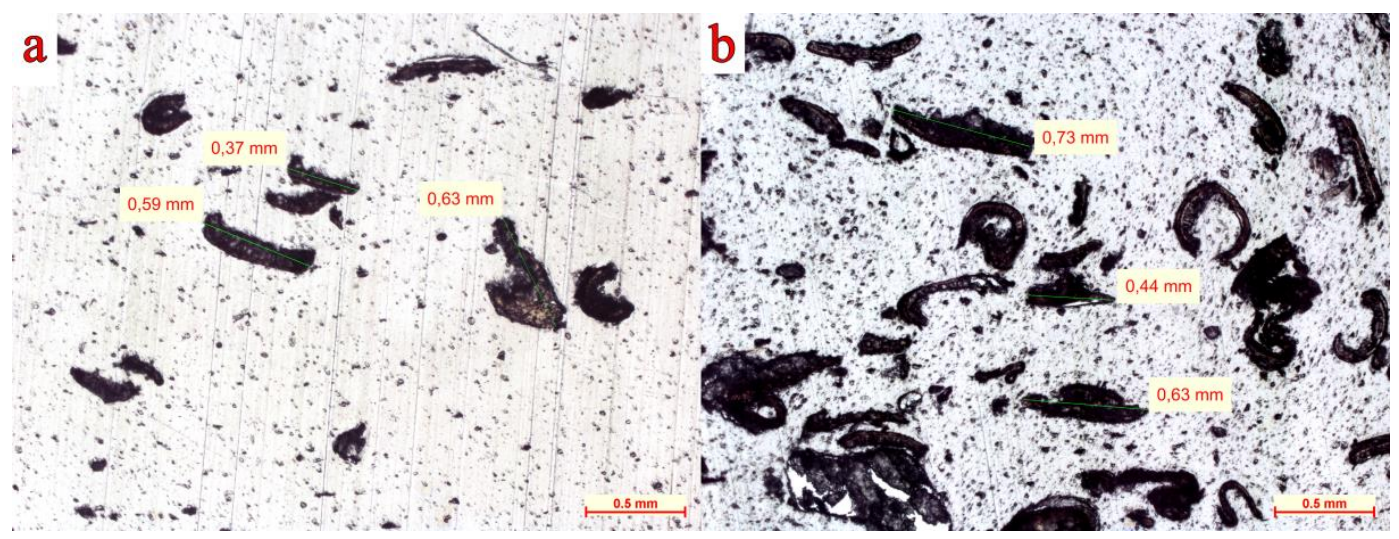

Fig. 13. Microscopic images of microstructures of the LDPE filled with WB with particle sizes in the range of $0.6 \mathrm{~mm}$ to $0.8 \mathrm{~mm}$ with a $5 \mathrm{wt} . \%$ (a) and $15 \mathrm{wt} \%$ content(b), dark areas represent WB

The analysis of the morphology showed an irregular distribution of the filler in the polymer matrix. The presence of particles with diverse sizes and shapes, as well as 
agglomerates, was noticeable. Unfortunately, the shape of certain particles was directly influenced by the nature of the milling process and the method of separation of particular size fractions of the filler. The WB particles with large sizes showed a tendency to curl because of their minimal rigidity, which can in turn influence the load transfer mechanism and resistance of the polymer composite. It was easy to see in the photographs that there was a noticeable increase in the number of particles smaller than what would typically appear in the used filler size fraction with an increase in the WB mass fraction. This suggested that a major part of the particles with low resistances was reduced in size by the screw in the plasticizing system. An asymmetrical shape of the filler particles and noticeable differences in the length, width, and thickness can result in disadvantageous asymmetry of properties from the point of view of a potential product.

\section{CONCLUSIONS}

1. Wheat bran may be effectively used as a polymer plastic filler in the injection molding process to create elements with low responsibility. The aim of the application of such a type of filler could be to lower the density of a plastic, reduce the production costs, and even to accelerate the process of degradation of the product once its operating period ends. However, it is necessary to select a suitable matrix to enable the process to be conducted at a relatively low temperature. It should be noted that adding a considerable amount of WB to the composition resulted in a noticeable decline in the mechanical properties of the composites.

2. The use of WB as a filler may prove somewhat problematic at the stage of establishing parameters for processing. Wheat bran may be employed as a filler only for plastics with a low plasticization temperature because it undergoes thermal decomposition within the plasticizing system when the temperature increases above $160^{\circ} \mathrm{C}$. Thermal decomposition leads to intense gas generation, uncontrolled ejection of the material from the plasticizing system, and the appearance of large-sized pores. Moreover, as the filler mass fraction increased, the viscosity of the material increased, which was why it exhibited an increasing resistance during processing.

3. The presence of WB in the LDPE matrix decreased the longitudinal shrinkage, which stabilized the size of ready-made injection molded samples. However, it should be noted that the WB, because of its hydrophilic properties, has an affinity for water, which increased the water absorption of the polymer composition as the mass fraction increased. In the presence of water and in high-humidity environments, this may lead to swelling and a change in the size of the molded samples. The effect of this affinity was more advanced when the particles were larger, and therefore there was more waterabsorbing surface. The intensity of the water absorbency was also influenced by the random factor responsible for the location of the WB particles next to the surface of the product.

4. As was shown in this and many other works, the use of powdered natural fillers as an additive in LDPE increased the Young's modulus, but it simultaneously decreased the tensile strength and resistance to tensile strain at break. This effect was more noticeable when the filler content was larger. Deterioration of the mechanical properties over the course of stretching could have resulted from major differences in the dimensions of 
individual WB particles and their curling, which consequently led to an asymmetry in the properties. Another reason could have been the considerable size of the particles in all three mass fractions, where cracks originated during stretching. The size of the particle had a substantial impact on the tensile strain at break. The tensile strain was larger when the particles were smaller.

\section{ACKNOWLEDGMENTS}

This project received funding from the European Union's Horizon 2020 research and innovation program under the Marie Skłodowska-Curie grant agreement (No. 734205).

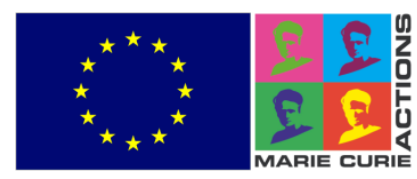

\section{REFERENCES CITED}

Abdul Karim, A. F., Ismail, H., and Ariff, Z. M. (2016). "Properties and characterization of kenaf-filled natural rubber latex foam," BioResources 11(1), 1080-1091.DOI: 10.15376/biores.11.1.1080-1091

Chiellini, E., Cinelli, P., Chiellini, F., and Imam, S. H. (2004). "Environmentally degradable bio-based polymeric blends and composites," Macromol.Biosci.4(3), 218231.DOI: $10.1002 / \mathrm{mabi} .200300126$

Chou, T. (1993).Materials Science and Technology, Volume 13: Structure and Properties of Composites, Verlagsgesellschaft, Weinheim, Germany.

Daud, S., Ismail, H., and AbuBakar, A. (2016). "Soil burial study of palm kernel shellfilled natural rubber composites: The effect of filler loading and presence of silane coupling agent," BioResources 11(4), 8686-8702.DOI: 10.15376/biores.11.4.86868702

Essabir, H., Hilali, E., Elgharad, A., El Minor, H., Imad, A., Elamraoui, A., and Al Graoudi, O. (2013). "Mechanical and thermal properties of bio-composites based on polypropylene reinforced with nut-shells of argan particles," Mater. Design 49, 442448.DOI: 10.1016/j.matdes.2013.01.025

Fisher, J. M. (2003). Handbook of Molded Part Shrinkage and Warpage, William Andrew Inc., Norwich, NY.

George, J., Kumar, R., Jayaprahash, C., Ramakrishna, A., Sabapathy, S. N., and Bawa, A. S. (2006). "Rice bran-filled biodegradable low-density polyethylene films: Development and characterization for packaging applications," J. Appl. Polym. Sci. 102(5), 4514-4522.DOI: 10.1002/app.24888

Głogowska, K., and Sikora, J. W. (2017). "Wpływ niemodyfikowanej neuburskiej glinki krzemianowej na właściwości przetwórcze i granulometryczne polietylenu dużej gęstości[Effect of untreated neuburg siliceous earth on the processing and granulometric properties of extruded high-density polyethylene]," Przem.Chem. 96(6), 1347-1351.DOI: 10.15199/62.2017.6.25 
Hardinnawirda, K., and SitiRabiatull Aisha, I. (2012)."Effect of rice husks as filler in polymer matrix composites," J. Mech. Eng. Sci. 2, 181-186.DOI:

10.15282/jmes.2.2012.5.0016

Hassan, A., Salema, A. A., Ani, F.N., and Abu Bakar, A. (2010). "A review on oil palm empty fruit bunch fiber-reinforced polymer composite materials," Polym. Composite. 31(12), 2079-2101.DOI: 10.1002/pc.21006

Hidaya, I.N., Mariatti, M., Ismail, H., and Kamarol, M. (2015). "Evaluation of PP/EPDM nanocomposites filled with $\mathrm{SiO}_{2}, \mathrm{TiO}_{2}$ and $\mathrm{ZnO}$ nanofillers as thermoplastic elastomeric insulators," Plast. Rubber Compos. 44(7), 259-264.DOI: 10.1179/1743289815Y.0000000014

ISO 1183-1 (2012). "Plastics - Methods for determining the density of non-cellular plastics. Part 1: Immersion method, liquid pyknometer method and titration method," International Organization for Standardization, Geneva, Switzerland.

ISO 294-1 (2017). "Plastics - Injection moulding of test specimens of thermoplastic materials. Part 1: General principles, and moulding of multipurpose and bar test specimens," International Organization for Standardization, Geneva, Switzerland.

ISO 294-4 (2001). "Plastics - Injection moulding of test specimens of thermoplastic materials. Part 4: Determination of moulding shrinkage," International Organization for Standardization, Geneva, Switzerland.

ISO 4649 (2017). "Rubber, vulcanized or thermoplastic - Determination of abrasion resistance using a rotating cylindrical drum device," International Organization for Standardization, Geneva, Switzerland.

ISO 527-1 (2012). "Plastics - Determination of tensile properties. Part 1: General principles," International Organization for Standardization, Geneva, Switzerland.

ISO 62 (2008). "Plastics - Determination of water absorption," International Organization for Standardization, Geneva, Switzerland.

ISO 868 (2003). "Plastics and ebonite - Determination of indentation hardness by means of a durometer (shore hardness)," International Organization for Standardization, Geneva, Switzerland.

Jagadish, R. S., Raj, B., and Asha, M. R. (2009). "Blending of low-density polyethylene with vanillin for improved barrier and aroma-releasing properties in food packaging," J.Appl.Polym.Sci.113(6), 3732-3741.DOI: 10.1002/app.30221

Katz, H., and Milewski, J. (1987).Handbook of Fillers for Plastics, Springer Science+Business Media, New York, NY.

Kim, G.-M., and Michler, G. H.(1998). "Micromechanical deformation processes in toughened and particle filled semicrystalline polymers: Part 2. Model representation for micromechanical deformation processes," Polymer 39(23), 5699-5703.DOI: 10.1016/S0032-3861(98)00169-4

Nuraya, A. S.S., Baharin, A., and Azura, A. R. (2015). "Influence of banana stem powder on knotty tear behaviour of prevulcanised natural rubber latex composite films," Plast. Rubber Compos. 44(7), 265-272.DOI: 10.1179/1743289815Y.0000000016

Osswald, T., Turng, L.-S., and Gramann, P. (2001).Injection Molding Handbook, Hanser Publisher, Munich, Germany.

Premalal, H.G. B., Ismail, H., and Baharin, A. (2002). "Comparison of the mechanical properties of rice husk powder filled polypropylene composites with talc filled polypropylene composites," Polym. Test. 21(7), 833-839.DOI: 10.1016/S01429418(02)00018-1 
Ramasamy, S., Ismail, H., and Munusamy, Y. (2013). "Effect of rice husk powder on compression behaviour and thermal stability of natural rubber latex foam," BioResources 8(3), 4258-4269.DOI: 10.15376/biores.8.3.4258-4269

Rao, K.M. M., Rao, K.M., and Prasad, A. V. R. (2010). "Fabrication and testing of natural fibre composites: Vakka, sisal, bamboo, and banana," Mater. Design 31(1), 508-513. DOI: 10.1016/j.matdes.20119.06.023

Rattanasom, N., Saowapark, T., and Deepprasertkul, C. (2007). "Reinforcement of natural rubber with silica/carbon black hybrid filler," Polym. Test. 26(3), 369377.DOI: 10.1016/j.polymertesting.2006.12.003

Rosato, D. V., and Rosato, M. G. (2000). Injection Molding Handbook, Kluwer Academic Publisher, Norwell, MA.

Rothon, R. (1999). "Mineral fillers in thermoplastics: Filler manufacture and characterisation," in: Mineral Fillers in Thermoplastics I. Advances in Polymer Science Volume 139,J. Jancar, E. Fekete, P. R. Hornsby, J. Jancar, B. Pukárnsky, and R. N. Rothon (eds.), Springer, Berlin, Germany,pp.67-107.

Rothon, R. (2003). Particulate-filled Polymer Composites, Second Edition, Smithers Rapra, Shawbury, UK.

Sikora, J. W., and Kapuśniak, T. (2005).“Efficiency of the extrusion process and characteristics of a conical-circular die," Polimery-W 50(10), 748-754.

Sikora, J. W., and Sasimowski, E. (2005). "Influence of the length of the plasticating system on selected characteristics of an auto thermal extrusion process," Adv. Polym. Tech. 24(1), 21-28.DOI: 10.1002/adv.20021

Statistical Yearbook of Agriculture (2010, 2012, 2014, 2016), Central Statistical Office, Warsaw, Poland.

Stevenson, L., Philips, F., O’Sullivan, K., Walton, J. (2012). "Wheat bran: Its composition and benefits to health, a European perspective," International Journal of Food and Sciences and Nutrition 63, 1001-1013.

Tjong, S. (2006). "Structural and mechanical properties of polymer nanocomposites," Mat. Sci. Eng. Res.53(3-4), 73-197.DOI: 10.1016/j.mser.2006.06.001

Xiang, B., Jiang, G., and Zhang, J. (2015). "Surface modification of $\mathrm{TiO}_{2}$ nanoparticles with silane coupling agent for nanocomposite with poly(butyl acrylate)," Plast. Rubber Compos. 44(4), 148-154.DOI: 10.1179/1743289815Y.0000000007

Zuiderduin, W.C. J., Westzaan, C., Huétink, J., and Gaymans, R. J. (2003). “Toughening of polypropylene with calcium carbonate particles," Polymer 44(1), 261-275.DOI: 10.1016/S0032-3861(02)00769-3.

Article submitted: April 11, 2018; Peer review completed: May 24, 2018; Revised version received: July 26, 2018; Accepted: July 27, 2018; Published: July 31, 2018. DOI: 10.15376/biores.13.3.7037-7052 